\title{
Results of weekday-on and weekend-off administration schedule of sunitinib therapy for advanced renal cell carcinoma
}

\author{
Atsunari Kawashima ${ }^{1} \cdot$ Motohide Uemura $^{1,2} \cdot$ Taigo Kato $^{1} \cdot$ Takeshi Ujike $^{1} \cdot$ Akira Nagahara $^{1} \cdot$ Kazutoshi Fujita $^{1}$. \\ Ryoichi Imamura' ${ }^{1}$ Yohei Yamanaka ${ }^{1,3}$. Eisuke Tomiyama' ${ }^{1}$. Go Tanigawa ${ }^{4}$. Yasushi Miyagawa ${ }^{5}$. Toshiaki Yoshioka ${ }^{5}$. \\ Osamu Miyake $^{6} \cdot$ Norio Nonomura $^{1}$
}

Received: 6 February 2018 / Accepted: 2 August 2018 / Published online: 9 August 2018

(c) The Author(s) 2018

\begin{abstract}
Background Sunitinib is widely prescribed as first-line therapy for metastatic renal cell carcinoma. To reduce the ratio of severe adverse events and improve the relative dose intensity, we prospectively tried our own alternative medication schedule, which we called the "weekday-on and weekend-off regimen". Here we report the results of this regimen compared to the conventional medication schedule.

Methods In total, 58 patients were enrolled in this study. Twenty patients were treated under the alternative schedule (group I: weekday-on and weekend-off regimen) and 38 patients were treated using the conventional schedule (group II: 4 weeks on and 2 weeks off regimen). The relative dose intensity (6W-RDI) and prognoses were compared between the two groups. Results Median 6W-RDI of all the patients was 75.0\%. Group I patients demonstrated significantly higher 6W-RDI compared to group II (77.2 vs. $70.4 \%)(p=0.019)$. Multivariate analysis showed that the alternative sunitinib administration schedule was significantly associated with maintaining 6W-RDI above 75\% for RCC patients treated with sunitinib (OR 3.592, 95\% CI 1.042-12.383, $p=0.043$ ). On the other hand, there were no significant differences between 2 groups regarding occurrence rate of severe adverse events and prognosis by multivariate analysis.

Conclusions We report the results of an alternative medication schedule, the "weekday-on and weekend-off regimen", as a means of increasing $6 \mathrm{~W}$-RDI for metastatic RCC patients.
\end{abstract}

Keywords Alternative schedule $\cdot$ Relative dose intensity $\cdot$ Molecular targeted therapy $\cdot$ Renal cell carcinoma $\cdot$ Sunitinib . Weekday-on · Weekend-off

Motohide Uemura

uemura@uro.med.osaka-u.ac.jp

1 Department of Urology, Graduate School of Medicine, Osaka University, 2-2 Yamadaoka, Suita, Osaka 5650871, Japan

2 Department of Therapeutic Urologic Oncology, Graduate School of Medicine, Osaka University, 2-2 Yamadaoka, Suita, Osaka 5650871, Japan

3 Department of Urology, Osaka Police Hospital, Osaka, Japan

4 Department of Urology, Osaka General Medical Center Hospital, Osaka, Japan

5 Department of Urology, Sumitomo Hospital, Osaka, Japan

6 Department of Urology, Toyonaka Municipal Hospital, Toyonaka, Osaka, Japan

\section{Introduction}

Since several oral receptor tyrosine kinase inhibitors (TKIs) and the mechanistic target of rapamycin (mTOR) inhibitors were approved for metastatic renal cell carcinoma (mRCC), sunitinib is widely prescribed as the first-line therapy for mRCC patients along with pazopanib, $[1,2]$ and the prognosis of mRCC patients has improved compared to the era of cytokine therapy [3, 4]. In the real-world setting, both global and Japanese case registration studies allowed for certain therapeutic effects and prolongation of progression-free survival and overall survival time $[5,6]$. Yet in addition to its therapeutic effect, treatment-related severe adverse events (AEs) appeared in some patients, leading to dose reduction and in some cases discontinuation of drug administration. Previously, we reported that maintenance of relative dose intensity (RDI) during the first course of 
treatment is important to improve the prognosis for $\mathrm{mRCC}$ patients treated by oral TKIs such as sunitinib $[7,8]$. To reduce the ratio of severe adverse events and get higher RDI, three alternative medication schedules for sunitinib therapy (continuous one-daily dosing regimen [9-11], 2 weeks on and 1 week off regimen [12-14] and weekday-on and weekend-off regimen [15]) have been pursued, including some prospective studies.

We prospectively tried to establish our own alternative medication schedule, which we called the "weekday-on and weekend-off regimen". Here we report the results of our prospective study and compare this regimen to the conventional medication schedule.

\section{Patients and methods}

\section{Patients enrolled in this study}

One hundred and nineteen RCC patients treated with sunitinib from 2010 to 2015 at Osaka University and its affiliated hospitals were collected in this study (Fig. 1a). In total, 52 patients were excluded due to pre-surgical setting $(n=9)$, 2nd line and more setting $(n=23)$, the usage of initial dose of $25 \mathrm{mg}$ per day $(n=20)$, prognosis unknown $(n=4)$ and data uncompleted $(n=5)$. Of 67 patients, 38 patients were treated under the conventional schedule (4 weeks on and 2 weeks off regimen: group I) and 20 patients were treated under the alternative schedule (weekday-on and weekend-off regimen: group II). The initially diagnosed tumours were staged according to the 7th American Joint Committee on Cancer staging classification [16]. The patient characteristics including laboratory findings were evaluated just before being treated with sunitinib medication. Clinical laboratory data collected for analysis included serum sodium concentration, estimated glomerular filtration ratio (eGFR) and $\mathrm{C}$-reactive protein (CRP).

\section{Alternative administration schedule}

Under our alternative schedule, sunitinib was administered only on 5 consecutive days for 2 weeks and 3 consecutive days for 1 week. The same dose intensity of conventional schedule was secured under the alternative schedule every 6 weeks as one course (Fig. 1b). Relative dose intensity for the first 6 weeks ( 6 weeks-RDI) was calculated as previously reported [7, 8]. Maximum RDI of general schedule and alternative schedule was $100 \%$. This alternative schedule was approved by institutional review board of all the participating institutions, and was registered with the Japanese
Fig. 1 a Criteria of the patient selection enrolled in this study. b Conventional schedule and alternative schedule. The numbers in the box represent the number of days

\section{(a)}

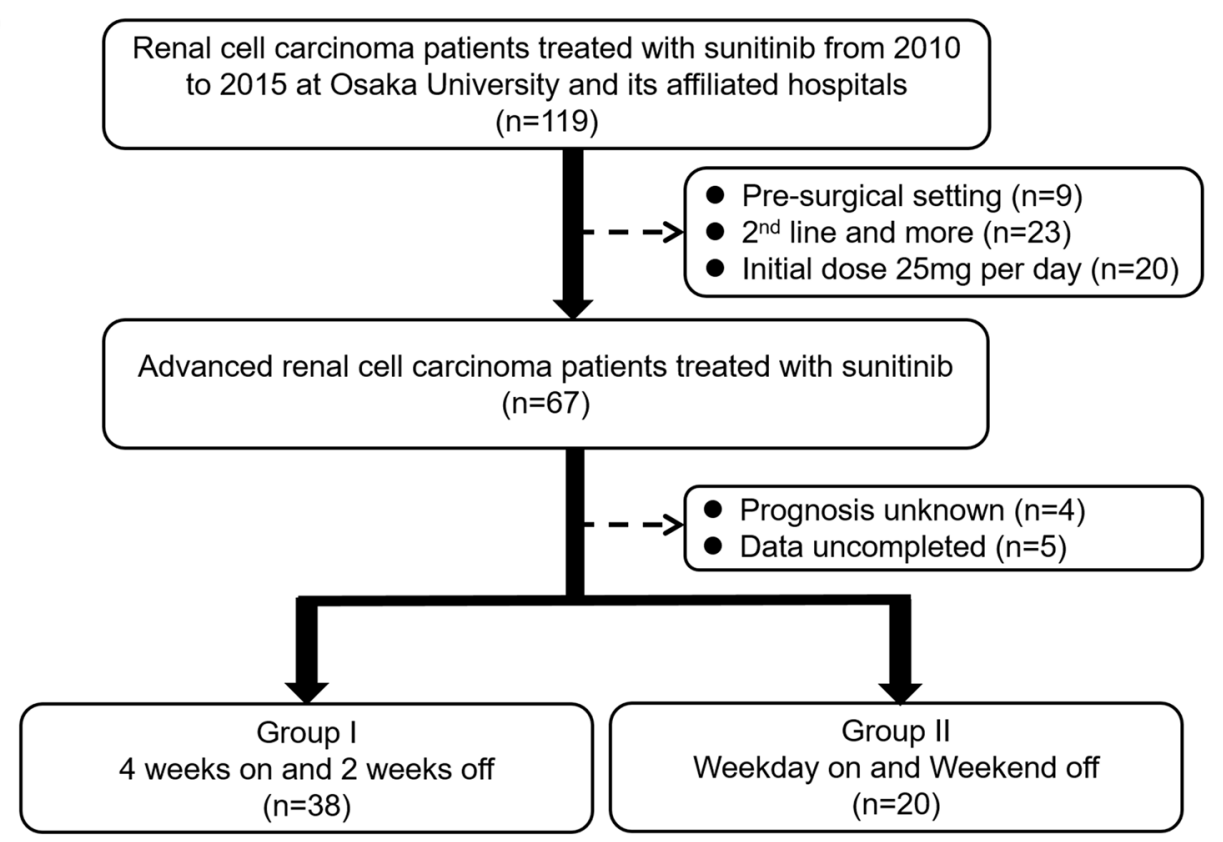

(b)

\begin{tabular}{|c|c|c|c|c|c|c|c|c|c|c|c|c|}
\hline $\begin{array}{c}\text { Standard Schedule } \\
\text { (Group I) }\end{array}$ & \multicolumn{8}{|c|}{28} & \multicolumn{4}{|c|}{14} \\
\hline $\begin{array}{c}\text { Alternative Schedule } \\
\text { (Group II) }\end{array}$ & 5 & 2 & 5 & 2 & 4 & 3 & 5 & 2 & 5 & 2 & 4 & 3 \\
\hline
\end{tabular}


University Hospital Medical Information Network clinical trial center (ID: UMIN000011649).

Selection of conventional schedule or alternative schedule was left to the judgement of each physician. Dose reductions and/or discontinuation were also applied in cases of disease progression, unacceptable toxicity or by decision of the physicians. Resuming the sunitinib medication was also left to decision of the physicians when medication was discontinued due to severe AEs or patient's preference.

\section{Follow-up regimens}

Patient's follow-up generally consisted of history, physical examination, routine blood work, abdominopelvic computed tomography (CT), and chest radiography. Elective bone scan and chest CT were performed when clinically indicated by several urologists. Tumor response was evaluated by the treating urologist every 1-3 months according to the Response Evaluation Criteria in Solid Tumors (RECIST) guidelines [17]. The AEs related to sunitinib therapy were recorded according to the National Cancer Institute's Common Terminology Criteria for Adverse Events version 4.0 [18].

\section{Statistical analysis}

The main objectives of this study were to compare the amount of 6W-RDI and the incidence of AEs between conventional and alternative schedule. Comparisons between the amount of 6W-RDI and clinical feature including administration schedule were evaluated by Mann-Whitney $U$ test and logistic regression analysis. Progression-free survival (PFS) time was measured from the date of initiation of sunitinib therapy until documented disease progression, death from disease progression, or the date of the patient's last follow-up visit. Distributions of PFS times were estimated with the Kaplan-Meier method, and associations between PFS and the clinical items were assessed with the log-rank test. As a multivariate analysis, Cox regression analysis using a step-wise forward selection with $p<0.1$ as the criterion for model entry or stay was used. Statistical analysis was performed with the Statistical Package for the Social Sciences software, version 20.0 (SPSS, Inc., Chicago, IL). A value of $p<0.05$ was considered statistically significant.

\section{Results}

\section{Patient characteristics}

Clinical characteristics of the 58 patients are described in Table 1. Median patient age was 66 (range 43-85) years, and 47 patients $(81.0 \%)$ were male. ECOG performance status of all the patients was 0 or 1 . The initial sunitinib dose was $50 \mathrm{mg}$ for 33 patients $(56.9 \%)$ and $37.5 \mathrm{mg}$ for the others. The initial dose was stratified by body surface area
Table 1 Characteristics of patients enrolled in this study

\begin{tabular}{|c|c|c|c|c|}
\hline & Total $(n=58)$ & Group I $(n=38)$ & Group II $(n=20)$ & $p$ \\
\hline Age (median) & $43-85(66)$ & $43-80(67.5)$ & $44-85(64.5)$ & 0.636 \\
\hline \multicolumn{5}{|l|}{ Gender } \\
\hline Male & 47 & 33 & 14 & \multirow[t]{2}{*}{0.163} \\
\hline Female & 11 & 5 & 6 & \\
\hline \multicolumn{5}{|l|}{ Initial sunitinib dose } \\
\hline $50 \mathrm{mg}$ & 33 & 23 & 10 & \multirow[t]{2}{*}{0.578} \\
\hline $37.5 \mathrm{mg}$ & 25 & 15 & 10 & \\
\hline \multicolumn{5}{|l|}{ Serum sodium concentration } \\
\hline$\leq 137 \mathrm{mEq} / \mathrm{L}$ & 22 & 13 & 9 & \multirow[t]{2}{*}{0.570} \\
\hline$\geq 138 \mathrm{mEq} / \mathrm{L}$ & 36 & 25 & 11 & \\
\hline \multicolumn{5}{|l|}{ Estimated GFR } \\
\hline$<44 \mathrm{~mL} / \mathrm{min} / 1.73 \mathrm{~m}^{2}$ & 23 & 15 & 8 & \multirow[t]{2}{*}{0.969} \\
\hline$\geq 44 \mathrm{~mL} / \mathrm{min} / 1.73 \mathrm{~m}^{2}$ & 35 & 23 & 12 & \\
\hline \multicolumn{5}{|l|}{ C-reactive protein } \\
\hline$<1 \mathrm{mg} / \mathrm{dL}$ & 39 & 28 & 11 & \multirow[t]{2}{*}{0.239} \\
\hline$\geq 1 \mathrm{mg} / \mathrm{dl}$ & 19 & 10 & 9 & \\
\hline $\begin{array}{l}\text { Discontinuation of sunitinib } \\
\text { within follow-up time }\end{array}$ & 14 & 9 & 5 & 0.911 \\
\hline $\begin{array}{l}\text { Relative dose intensity for } \\
\text { initial } 6 \text { weeks (\%) (raw } \\
\text { data) }\end{array}$ & $27-100(75.0)$ & $27-100(70.4)$ & $38.0-100(77.2)$ & 0.019 \\
\hline
\end{tabular}

ECOG Eastern Cooperative Oncology Group, GFR glomerular filtration rate 
$\left(50 \mathrm{mg} /\right.$ day $\geq 1.6 \mathrm{~m}^{2}, 37.5 \mathrm{mg} /$ day $\left.<1.6 \mathrm{~m}^{2}\right)$. Twenty-two patients $(37.9 \%)$ had hyponatremia (137 mEq/L and less). Estimated GFR of 23 patients $(39.7 \%$ ) was less than $44 \mathrm{~mL} /$ $\min / 1.72 \mathrm{~m}^{2}$, which was defined as stage $3 \mathrm{~b}$ and more of chronic kidney disease. CRP of 19 patients (32.8\%) was $1 \mathrm{mg} / \mathrm{dL}$ and more.

\section{Relative dose intensity for initial 6 weeks according to the schedule of sunitinib administration}

Median 6W-RDI of all the patients was $75.0 \%$ (27-100\%). In the " 4 week on and 2 week off regimen" group, median $6 \mathrm{~W}-\mathrm{RDI}$ was $70.4 \%(27-100 \%)$, whereas in the "weekdayon and weekend-off regimen" group, median 6W-RDI was $77.2 \%(38-100 \%)$. The 6W-RDI of group II was significantly higher than that of group I ( $p=0.019)$ (Fig. 2).

Overall, 33 patients $(56.9 \%)$ achieved $75 \%$ and more $6 \mathrm{~W}-\mathrm{RDI}$. Fifteen patients $(75.0 \%)$ in group I and 18

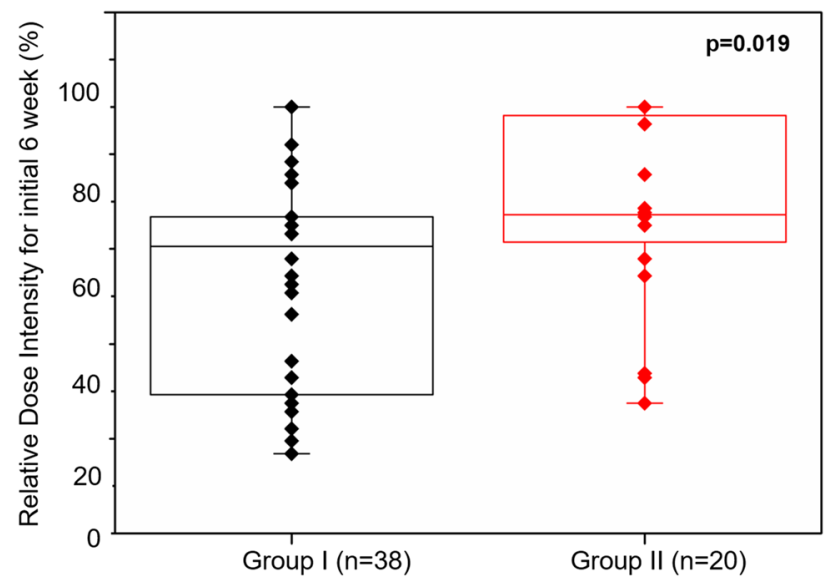

Fig. 2 Relative dose intensity for initial 6 weeks according to the schedule of sunitinib administration. Statistical analysis was performed by Mann-Whitney's test. Group I: 4 weeks on/2 weeks off, Group II: weekday-on/weekend-off patients (47.4\%) in group II were able to achieve $75 \%$ and more 6W-RDI. Statistically, only the alternative sunitinib administration schedule was significantly correlated [odds ratio (OR) 3.333, 95\% confidence interval (CI) 1.008-11.020, $p=0.048$ ]. In multivariate analysis, the alternative sunitinib administration schedule was shown to be an important clinical feature for maintaining high 6W-RDI for RCC patients treated by sunitinib (OR 3.592, 95\% CI 1.042-12.383, $p=0.043$ ) (Table 2).

\section{Severe adverse events (Grade 3 and 4) stratified by administration schedule}

In total, nine patients (15.5\%) suffered from severe (Grade 3 or 4) AEs within one course (Table 3). There were no patients with Grade 5 AEs. Six patients (15.8\%) in group I and 1 patient $(5.0 \%)$ in group II had severe thrombocytopenia. Occurrence rate of group I was higher than that of group II although the difference was not significant $(p=0.403)$. Severe liver dysfunction, hypertension, and hand-foot skin reaction occurred in each one patient of group II. In addition, general fatigue has occurred in one patient of group I.

Table 3 Severe adverse events (Grade 3 and 4) stratified by administration schedule

\begin{tabular}{llll}
\hline $\begin{array}{l}\text { Adverse events (Grade } \\
3 \text { or 4) }\end{array}$ & Group I $(\mathrm{n}=38)$ & Group II $(\mathrm{n}=20)$ & $p$ \\
\hline Thrombocytopenia & $6(15.8 \%)$ & $1(5.0 \%)$ & 0.403 \\
Liver dysfunction & 0 & $1(5.0 \%)$ & 0.345 \\
Hypertension & 0 & $1(5.0 \%)$ & 0.345 \\
Hand-foot skin reaction & 0 & $1(5.0 \%)$ & 0.345 \\
General fatigue & $1(2.6 \%)$ & 0 & 1.000 \\
\hline
\end{tabular}

Table 2 Result of univariate and multivariate analysis about the clinical features significantly correlated with achievement of relative dose intensity more than $75 \%$. Statistical analysis was performed by logistic regression analysis

\begin{tabular}{|c|c|c|c|c|c|c|}
\hline \multirow[t]{2}{*}{ Clinical features } & \multicolumn{3}{|c|}{ Univariate analysis } & \multicolumn{3}{|c|}{ Multivariate analysis } \\
\hline & OR & $95 \% \mathrm{CI}$ & $p$ & OR & $95 \% \mathrm{CI}$ & $p$ \\
\hline Age (median) $(<65$ vs. $\geq 65)$ & 0.943 & $0.331-2.682$ & 0.912 & & & \\
\hline Gender (male vs. female) & 0.889 & $0.237-3.328$ & 0.861 & & & \\
\hline Initial sunitinib dose (50 vs. $37.5 \mathrm{mg}$ ) & 0.527 & $0.183-1.519$ & 0.236 & & & \\
\hline Sunitinib administration schedule (Group I vs. Group II) & 3.333 & $1.008-11.020$ & 0.048 & 3.592 & $1.042-12.383$ & 0.043 \\
\hline Serum sodium concentration $(\leq 137 \mathrm{mEq} / \mathrm{l}$ vs. $\geq 138 \mathrm{mEq} / \mathrm{l})$ & 0.467 & $0.154-1.416$ & 0.178 & & & \\
\hline Estimated GFR $\left(<44 \mathrm{~mL} / \mathrm{min} / 1.73 \mathrm{~m} 2 \mathrm{vs} . \geq 44 \mathrm{~mL} / \mathrm{min} / 1.73 \mathrm{~m}^{2}\right)$ & 2.492 & $0.846-7.338$ & 0.098 & 2.713 & $0.871-8.451$ & 0.085 \\
\hline C-reactive protein $(<1 \mathrm{mg} / \mathrm{dL}$ vs. $\geq 1 \mathrm{mg} / \mathrm{dL})$ & 1.062 & $0.350-3.221$ & 0.915 & & & \\
\hline
\end{tabular}

$O R$ odds ratio, $C I$ confidence interval, GFR glomerular filtration rate 


\section{PFS of total cases and stratified by some clinical characteristics}

The median PFS of total cases was 10.2 months (95\% CI 4.1-16.3) (Fig. 3a). In subgroup analyses, there was no significant difference in PFS between " 4 week on and 2 week off regimen" and "weekday-on and weekend-off regimen" (7.4 vs. 10.2 months, $p=0.528$ ) (Fig. 3b). PFS of the patients with $75 \%$ and more $6 \mathrm{~W}$-RDI was better than that of patients with less than $75 \%$ 6W-RDI $(10.3$ vs. 4.3 months, $p=0.068$ ) (Fig. 3c). PFS of patients with high CRP (1 $\mathrm{mg} / \mathrm{dL}$ and more) was shorter than that of patients with low CRP (less than $1 \mathrm{mg} / \mathrm{dL})(2.3 \mathrm{vs}$. 23.4 months, $p<0.001$ ) (Fig. 3d).

In multivariate Cox regression analysis, low CRP (less than $1 \mathrm{mg} / \mathrm{dL}$ ) [hazard ratio (HR) 3.014, 95\% CI 1.587-5.725, $p<0.001]$ was identified as independent predictor of superior PFS time (Table 4).

\section{Clinical features significantly correlated with discontinuation rate due to adverse events}

The median discontinuation time due to severe AEs of total cases was 27.5 months (95\% CI 0.0-59.5) (Fig. 4a). In subgroup analyses, there was no significant difference regarding discontinuation time between the " 4 weeks on and 2 weeks off regimen" group and the "weekdayon and weekend-off regimen" group (15.4 months vs. not reached, $p=0.178$ ) (Fig. 4b). Discontinuation time for patients with hyponatremia (less than $138 \mathrm{mEq} / \mathrm{L}$ ) was shorter than that of patients with normal sodium concentration (138 mEq/L and more) (4.1 months vs. 38.4 months, $p=0.074$ ) (Fig. 4c). Discontinuation time of patients with impaired kidney function (less than $44 \mathrm{~mL} /$ $\min / 1.73 \mathrm{~m}^{2}$ ) tended to be shorter than that of patients with normal kidney function $\left(44 \mathrm{~mL} / \mathrm{min} / 1.73 \mathrm{~m}^{2}\right.$ and more) (3.3 months vs. 38.4 months, $p=0.011$ ) (Fig. $4 \mathrm{~d}$ ).
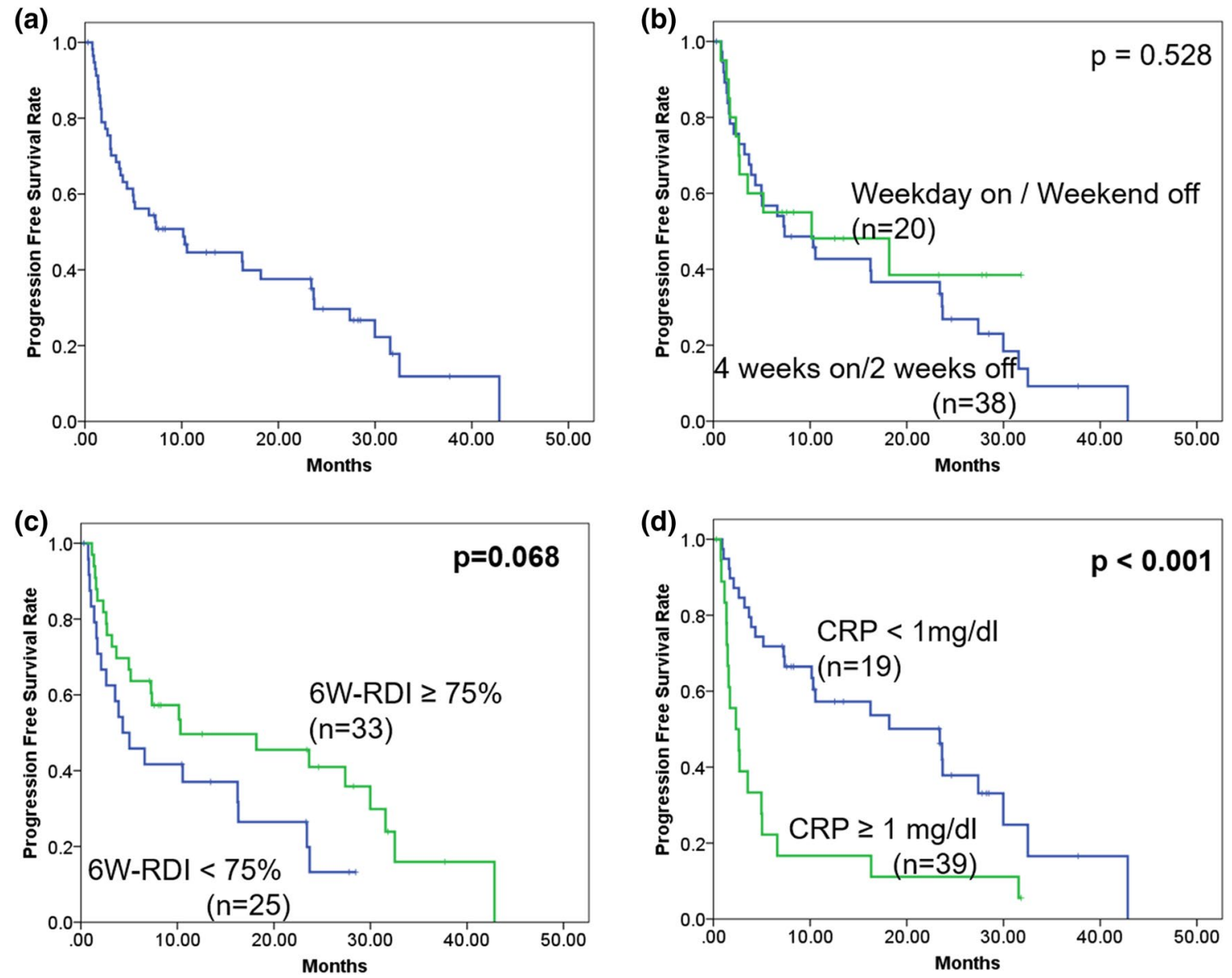

Fig. 3 Progression-free survival curve of total cases (a) and stratified by administration schedule (b), relative dose intensity for initial 6 weeks (6W-RDI) (c) and C-reactive protein (CRP) (d). Statistical analysis was performed using log-rank test 
Table 4 Result of univariate and multivariate analysis about the clinical features significantly correlated with progression-free survival. Statistical analysis performed using Cox regression analysis

\begin{tabular}{|c|c|c|c|c|c|c|}
\hline \multirow[b]{2}{*}{ Clinical features } & \multicolumn{3}{|c|}{ Univariate analysis } & \multicolumn{3}{|c|}{ Multivariate analysis } \\
\hline & HR & $95 \% \mathrm{CI}$ & $p$ & HR & $95 \% \mathrm{CI}$ & $p$ \\
\hline Age $($ median $)(<65$ vs. $\geq 65)$ & 1.382 & $0.736-2.597$ & 0.314 & & & \\
\hline Gender (male vs. female) & 0.716 & $0.299-1.713$ & 0.453 & & & \\
\hline Initial sunitinib dose (50 mg vs. $37.5 \mathrm{mg}$ ) & 0.960 & $0.513-1.797$ & 0.899 & & & \\
\hline Sunitinib administration schedule (Group I vs. Group II) & 0.799 & $0.398-1.605$ & 0.529 & & & \\
\hline Serum sodium concentration $(\leq 137 \mathrm{mEq} / \mathrm{L}$ vs. $\geq 138 \mathrm{mEq} / \mathrm{L})$ & 0.654 & $0.344-1.244$ & 0.195 & & & \\
\hline Estimated GFR ( $<44 \mathrm{~mL} / \mathrm{min} / 1.73 \mathrm{~m}^{2}$ vs. $\left.\geq 44 \mathrm{~mL} / \mathrm{min} / 1.73 \mathrm{~m}^{2}\right)$ & 1.348 & $0.725-2.509$ & 0.346 & & & \\
\hline C-reactive protein $(<1 \mathrm{mg} / \mathrm{dL}$ vs. $\geq 1 \mathrm{mg} / \mathrm{dL})$ & 3.014 & $1.587-5.725$ & 0.001 & 3.044 & $1.602-5.783$ & 0.001 \\
\hline Relative dose intensity for initial 6 weeks ( $<75 \%$ vs. $\geq 75 \%)$ & 0.556 & $0.293-1.055$ & 0.072 & 0.545 & $0.286-1.040$ & 0.065 \\
\hline
\end{tabular}

$H R$ hazard ratio, $C I$ confidence interval, GFR glomerular filtration rate

(a)

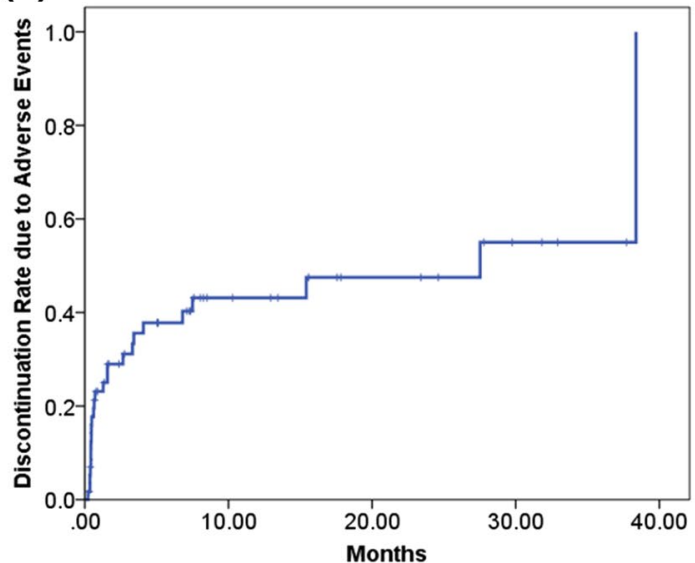

(c)

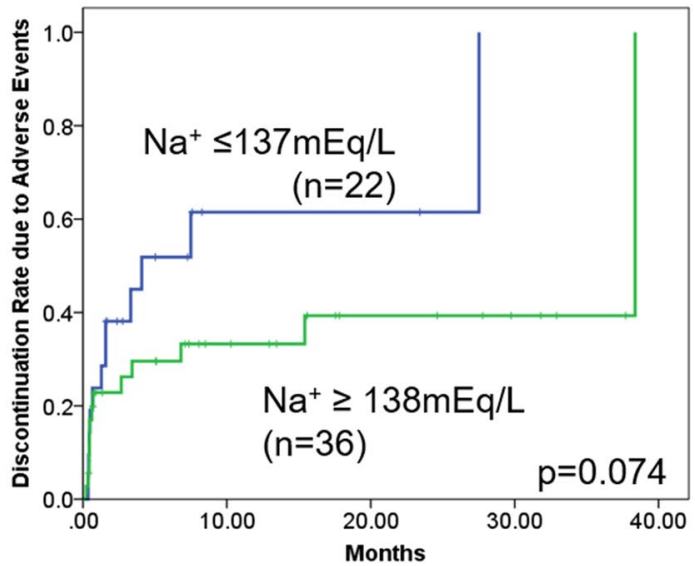

(b)

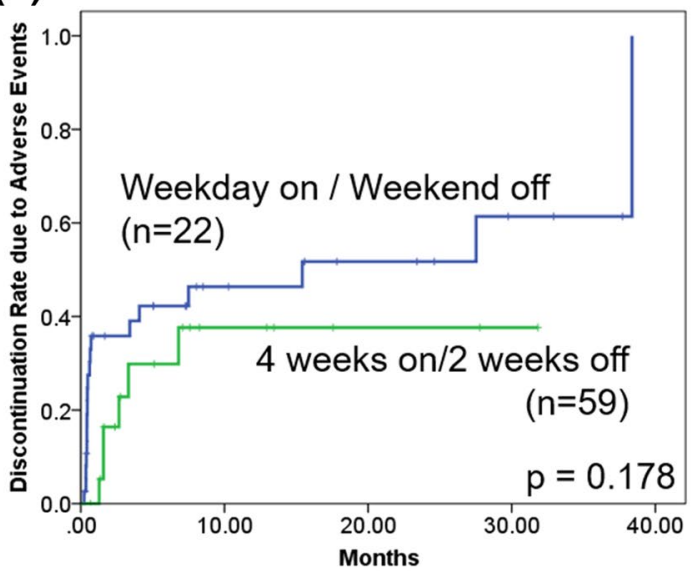

(d)

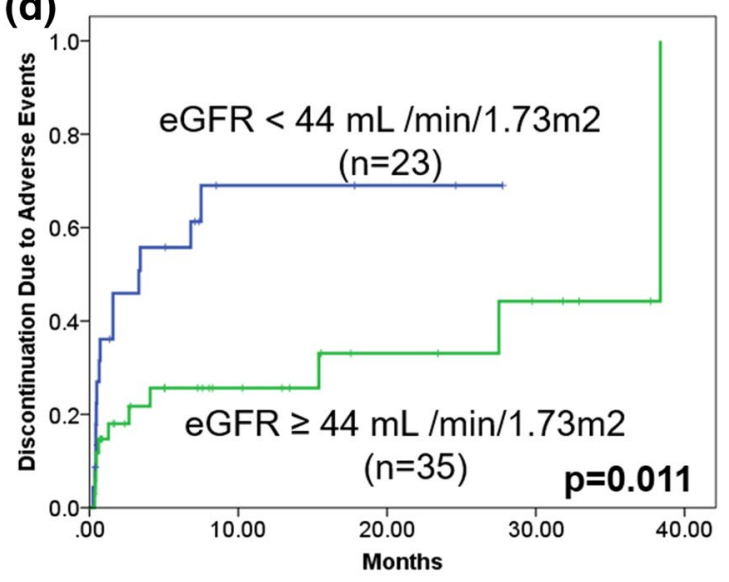

Fig. 4 Discontinuation rate curve due to adverse events of total cases (a), stratified by administration schedule (b), serum sodium concentration $\left(\mathrm{Na}^{+}\right)(\mathbf{c})$ and estimated glomerular filtration rate (eGFR) (d). Statistical analysis was performed using log-rank test

In multivariate Cox regression analysis, hyponatremia (less than $138 \mathrm{mEq} / \mathrm{L})$ (HR 2.501, 95\% CI 1.089-5.747, $p=0.031$ ) and impaired kidney function (less than $44 \mathrm{~mL} /$ $\left.\mathrm{min} / 1.73 \mathrm{~m}^{2}\right)($ HR 3.216, 95\% CI 1.395-7.412, $p=0.006)$ were identified as independent predictors of inferior discontinuation time (Table 5). 
Table 5 Result of univariate and multivariate analysis about the clinical features significantly correlated with discontinuation rate due to adverse events. Statistical analysis was performed by Cox regression analysis

\begin{tabular}{|c|c|c|c|c|c|c|}
\hline \multirow[t]{2}{*}{ Clinical features } & \multicolumn{3}{|c|}{ Univariate analysis } & \multicolumn{3}{|c|}{ Multivariate analysis } \\
\hline & HR & $95 \% \mathrm{CI}$ & $p$ & HR & $95 \% \mathrm{CI}$ & $p$ \\
\hline Age $($ median $)(<65$ vs. $\geq 65)$ & 1.865 & $0.797-4.363$ & 0.151 & & & \\
\hline Gender (male vs. female) & 0.554 & $0.165-1.862$ & 0.340 & & & \\
\hline Initial sunitinib dose (50 mg vs. $37.5 \mathrm{mg})$ & 1.496 & $0.669-3.345$ & 0.327 & & & \\
\hline Sunitinib administration schedule (Group I vs. Group II) & 0.534 & $0.211-1.351$ & 0.185 & & & \\
\hline Serum sodium concentration $(\leq 137 \mathrm{mEq} / \mathrm{L}$ vs. $\geq 138 \mathrm{mEq} / \mathrm{L})$ & 2.064 & $0.915-4.656$ & 0.081 & 2.501 & $1.089-5.747$ & $\mathbf{0 . 0 3 1}$ \\
\hline Estimated GFR $\left(<44 \mathrm{~mL} / \mathrm{min} / 1.73 \mathrm{~m}^{2}\right.$ vs. $\left.\geq 44 \mathrm{~mL} / \mathrm{min} / 1.73 \mathrm{~m}^{2}\right)$ & 2.780 & $1.224-6.316$ & 0.015 & 3.216 & $1.395-7.412$ & 0.006 \\
\hline C-reactive protein $(<1 \mathrm{mg} / \mathrm{dL}$ vs. $\geq 1 \mathrm{mg} / \mathrm{dL})$ & 1.091 & $0.444-2.682$ & 0.849 & & & \\
\hline
\end{tabular}

$H R$ hazard ratio, $C I$ confidence interval, GFR glomerular filtration rate

\section{Discussions}

Sunitinib is currently used as the first-line therapy for patients with metastatic or advanced RCC. Yet in addition to its efficacy as an anti-cancer agent, it often leads to serious side effects, requiring medication interruption or discontinuation in some patients [19]. Previous studies, including reports from our group, have shown that maintaining high RDI with molecular-targeted therapy improves the prognosis of RCC patients [6-8]. Thus, in an effort to reduce the occurrence rate of serious AEs while maintaining a high RDI, several groups have piloted new treatment regimens as alternatives to the conventional "4 weeks on and 2 weeks off regimen", with some success. Here, we report the results of an alternative medication schedule, the "weekday-on and weekend-off regimen", of sunitinib therapy for metastatic RCC patients.

As noted above, a number of alternative treatment regimens for sunitinib have been reported in the literature. Escudier et al. first reported phase II results of the "continuous one-daily dosing regimen" for cytokine-refractory patients. The median PFS time was 8.3 months, and the interruption and discontinuation rates were 65 and $78 \%$, respectively. Severe adverse events included general fatigue (16\%), diarrhea (12\%), and hypertension (11\%) [9]. Barrios et al. reported phase II results of the same regimen applied as the first-line treatment. Their median PFS time was 6.1 months, and interruption and discontinuation rate were $18 \%$ and $65 \%$, respectively. Severe adverse events included hand-foot syndrome (13\%), neutropenia (11\%), and diarrhea (9\%) [10]. Although the results of these studies appeared promising, a randomized phase II trial, which compared the efficacy between the "4 weeks on and 2 weeks off regimen" and "continuous one-daily dosing regimen", proved that the conventional method was able to obtain better PFS than the alternative method [11]. Their results also indicated that the occurrence rate of severe AEs was almost the same between the two groups.
Subsequently, Najjar et al. reported the results of another alternative method, " 2 weeks on and 1 week off regimen" [14]. They reported that severe AEs such as general fatigue or hand-foot syndrome were significantly reduced in this regimen as compared to the conventional method. Also, Bracarda et al. reported that the PFS time of the 208 patients whose medication methods were changed from conventional to the alternative method when severe AEs occurred was much better than the PFS of patients treated only by the conventional method $(n=211)$ or only by the alternative method $(n=41)$. The occurrence rate of AEs decreased in the alternative method group compared to conventional method group [12]. Recently, Lee et al. reported the results of a randomized phase II trial which compared the clinical utility of the " 4 weeks on and 2 weeks off regimen" vs. the " 2 weeks on and 1 week off regimen" [13]. In their RESTORE trial, they proved that the " 2 weeks on and 1 week off regimen" demonstrated better failure free survival (FFS) than the "4 weeks on and 2 weeks off regimen" (median FFS 7.6 months vs. 6.0 months, $p=0.029$ ) though there was no significant difference about PFS.

At the same time as these studies, we prospectively tried a "weekday-on and weekend-off regimen" as an alternative method of sunitinib therapy. Using historical controls for comparison, patients treated under the "weekday-on and weekend-off regimen" could achieve higher 6W-RDI than patients treated under the " 4 weeks on and 2 weeks off regimen". Also, the number of the patients who could get $75 \%$ and more 6W-RDI were statistically higher in the "weekday-on and weekend-off regimen" compared to those in the " 4 weeks on and 2 weeks off regimen".

In Japanese patients, severe thrombocytopenia occurred more often than in Western patients [5, 6]. In our cohort, severe thrombocytopenia was the most common AE. In terms of severe thrombocytopenia, the occurrence rate in "weekday-on and weekend-off regimen" was lower than in the " 4 weeks on and 2 weeks off regimen", although this difference did not achieve significance. This may explain 
why patients treated under the "weekday-on and weekendoff regimen" achieved higher 6W-RDI than those treated under the "4 weeks on and 2 weeks off regimen".

Unfortunately, PFS for the "weekday-on and weekendoff regimen" was not improved compared to the "4 weeks on and 2 weeks off regimen" in both univariate and multivariate analysis. PFS of the patients treated with sunitinib in the general practice ranged from 5.7 to 9.4 months [5, 6], although PFS was much better in the clinical trials $[3,4,20]$. Total PFS in our cohort was similar to that of previous studies of general practice. CRP became statistically significant prognostic factor and higher 6W-RDI was tended to become significant prognostic factor in our cohort, as has been previously reported $[6,21]$. Actually, 2 -year PFS ratio of "weekday-on and weekend-off regimen" $(58.4 \%)$ tended to be longer than that of " 4 weeks on and 2 weeks off regimen" (31.9\%) in 39 patients with lower CRP $(p=0.10)$ though that of "weekday-on and weekend-off regimen" (11.1\%) was almost the same as that of " 4 weeks on and 2 weeks off regimen" (11.1\%) in 19 patients with higher CRP (data not shown). Collectively these results indicate that urologists and medical oncologists should seek alternative treatment regimens that maximize tolerated $6 \mathrm{~W}-\mathrm{RDI}$ for RCC patients with better prognostic factors such as lower CRP level.

In this study, discontinuation of sunitinib therapy was significantly correlated with the presence of hyponatremia and renal impairment. Chronic kidney disease was already reported to be significantly associated with toxicity-related treatment discontinuation [22, 23]. Hyponatremia is wellknown to be correlated with poor prognosis in RCC patients treated with molecular-targeted therapy [24-26]. This is the first study to indicate that the presence of hyponatremia was significantly correlated with discontinuation of therapy in multivariate analysis. So, these patients should be treated more carefully along with modification of administration method because sunitinib therapy should be interrupted despite the therapeutic effect.

This study was subject to several limitations. This study was not a randomized control study, and the number of the patients enrolled was small. Nonetheless, we could achieve an improved 6W-RDI in our cohort, and this "weekday-on and weekend-off regimen" could be considered to manage patients to get prolonged PFS in general practice.

In conclusion, we report here the results of an alternative medication schedule, the "weekday-on and weekday-off regimen", and suggest that this alternative could improve $6 \mathrm{~W}-\mathrm{RDI}$ in patients, a metric correlated with improved prognosis, and reduce the occurrence rate of severe AEs, although this difference did not achieve significance.
Acknowledgements This research did not receive any specific grant from any funding agency in the public, commercial or not-for-profit sector.

\section{Compliance with ethical standards}

Conflict of interest Norio Nonomura received research grant and lecture fees from Astellas Pharma and Takeda Pharmaceutical.

Open Access This article is distributed under the terms of the Creative Commons Attribution 4.0 International License (http://creativeco mmons.org/licenses/by/4.0/), which permits unrestricted use, distribution, and reproduction in any medium, provided you give appropriate credit to the original author(s) and the source, provide a link to the Creative Commons license, and indicate if changes were made.

\section{References}

1. Escudier B, Porta C, Schmidinger M et al (2016) Renal cell carcinoma: ESMO Clinical Practice Guidelines for diagnosis, treatment and follow-up. Ann Oncol 27:v58-v68. https://doi. org/10.1093/annonc/mdw328

2. Ljungberg B, Bensalah K, Canfield S et al (2015) EAU guidelines on renal cell carcinoma: 2014 update. Eur Urol 67(5):913-924. https://doi.org/10.1016/j.eururo.2015.01.005

3. Motzer RJ, Hutson TE, Tomczak P et al (2007) Sunitinib versus interferon alfa in metastatic renal-cell carcinoma. N Engl J Med 356(2):115-124. https://doi.org/10.1056/NEJMoa065044

4. Motzer RJ, Hutson TE, Tomczak P et al (2009) Overall survival and updated results for sunitinib compared with interferon alfa in patients with metastatic renal cell carcinoma. J Clin Oncol 27(22):3584-3590. https://doi.org/10.1200/JCO.2008.20.1293

5. Gore ME, Szczylik C, Porta C et al (2015) Final results from the large sunitinib global expanded-access trial in metastatic renal cell carcinoma. Br J Cancer 113(1):12-19. https://doi.org/10.1038/ bjc. 2015.196

6. Akaza H, Naito S, Ueno N et al (2015) Real-world use of sunitinib in Japanese patients with advanced renal cell carcinoma: efficacy, safety and biomarker analyses in 1689 consecutive patients. Jpn J Clin Oncol 45(6):576-583. https://doi.org/10.1093/jjco/hyv045

7. Kawashima A, Tsujimura A, Takayama $\mathrm{H}$ et al (2012) Importance of continuing therapy and maintaining one-month relative dose intensity in sunitinib therapy for metastatic renal cell carcinoma. Med Oncol 29(5):3298-3305. https://doi.org/10.1007/s1203 2-012-0236-6

8. Kawashima A, Takayama H, Arai Y et al (2011) One-month relative dose intensity of not less than $50 \%$ predicts favourable progression-free survival in sorafenib therapy for advanced renal cell carcinoma in Japanese patients. Eur J Cancer 47(10):1521-1526. https://doi.org/10.1016/j.ejca.2011.04.001

9. Escudier B, Roigas J, Gillessen S et al (2009) Phase II study of sunitinib administered in a continuous once-daily dosing regimen in patients with cytokine-refractory metastatic renal cell carcinoma. J Clin Oncol 27(25):4068-4075. https://doi.org/10.1200/ JCO.2008.20.5476

10. Barrios CH, Hernandez-Barajas D, Brown MP et al (2012) Phase II trial of continuous once-daily dosing of sunitinib as first-line treatment in patients with metastatic renal cell carcinoma. Cancer Am Cancer Soc 118(5):1252-1259. https://doi.org/10.1002/ cncr. 26440 
11. Motzer RJ, Hutson TE, Olsen MR et al (2012) Randomized phase II trial of sunitinib on an intermittent versus continuous dosing schedule as first-line therapy for advanced renal cell carcinoma. J Clin Oncol 30(12):1371-1377. https://doi.org/10.1200/ JCO.2011.36.4133

12. Bracarda S, Iacovelli R, Boni L et al (2016) Sunitinib administered on $2 / 1$ schedule in patients with metastatic renal cell carcinoma: the RAINBOW analysis. Ann Oncol 27(2):366. https://doi. org/10.1093/annonc/mdv589

13. Lee JL, Kim MK, Park I et al (2015) RandomizEd phase II trial of sunitinib four weeks on and two weeks off versus two weeks on and one week off in metastatic clear-cell type REnal cell carcinoma: RESTORE trial. Ann Oncol 26(11):2300-2305. https:// doi.org/10.1093/annonc/mdv357

14. Najjar YG, Mittal K, Elson P et al (2014) A 2 weeks on and 1 week off schedule of sunitinib is associated with decreased toxicity in metastatic renal cell carcinoma. Eur J Cancer 50(6):10841089. https://doi.org/10.1016/j.ejca.2014.01.025

15. Buti S, Donini M, Lazzarelli S et al (2012) A new modified schedule of sunitinib for metastatic renal cell carcinoma: a retrospective analysis. Acta Biomed 83(2):88-94

16. Edge SB, American Joint Committee on Cancer (2010) AJCC cancer staging manual, 7 th edn. Springer, New York

17. Eisenhauer EA, Therasse P, Bogaerts J et al (2009) New response evaluation criteria in solid tumours: revised RECIST guideline (version 1.1). Eur J Cancer 45(2):228-247. https://doi. org/10.1016/j.ejca.2008.10.026

18. National Cancer Institute (US) (2009) Common terminology criteria for adverse events (CTCAE). In: NIH publication, rev. edn, vol 10-5410. US Department of Health and Human Services, National Institutes of Health, National Cancer Institute, Bethesda

19. Prasad V, Massey PR, Fojo T (2014) Oral anticancer drugs: how limited dosing options and dose reductions may affect outcomes in comparative trials and efficacy in patients. J Clin Oncol 32(15):1620-1629. https://doi.org/10.1200/JCO.2013.53.0204
20. Uemura H, Shinohara N, Yuasa T et al (2010) A phase II study of sunitinib in Japanese patients with metastatic renal cell carcinoma: insights into the treatment, efficacy and safety. Jpn J Clin Oncol 40(3):194-202. https://doi.org/10.1093/jjco/hyp146

21. Saito K, Tatokoro M, Fujii Y et al (2009) Impact of C-reactive protein kinetics on survival of patients with metastatic renal cell carcinoma. Eur Urol 55(5):1145-1153. https://doi.org/10.1016/j. eururo.2008.10.012

22. Kaymakcalan MD, Xie W, Albiges L et al (2016) Risk factors and model for predicting toxicity-related treatment discontinuation in patients with metastatic renal cell carcinoma treated with vascular endothelial growth factor-targeted therapy: results from the International Metastatic Renal Cell Carcinoma Database Consortium. Cancer Am Cancer Soc 122(3):411-419. https://doi.org/10.1002/ cncr. 29773

23. Nouhaud FX, Pfister C, Defortescu G et al (2015) Baseline chronic kidney disease is associated with toxicity and survival in patients treated with targeted therapies for metastatic renal cell carcinoma. Anticancer Drugs 26(8):866-871. https://doi.org/10.1097/ CAD.0000000000000253

24. Kawashima A, Tsujimura A, Takayama H et al (2012) Impact of hyponatremia on survival of patients with metastatic renal cell carcinoma treated with molecular targeted therapy. Int J Urol 19(12):1050-1057. https://doi.org/10.111 1/j.1442-2042.2012.03115.x

25. Furukawa J, Miyake H, Kusuda Y et al (2015) Hyponatremia as a powerful prognostic predictor for Japanese patients with clear cell renal cell carcinoma treated with a tyrosine kinase inhibitor. Int J Clin Oncol 20(2):351-357. https://doi.org/10.1007/s1014 7-014-0713-3

26. Schutz FA, Xie W, Donskov F et al (2014) The impact of low serum sodium on treatment outcome of targeted therapy in metastatic renal cell carcinoma: results from the International Metastatic Renal Cell Cancer Database Consortium. Eur Urol 65(4):723-730. https://doi.org/10.1016/j.eururo.2013.10.013 